\title{
NEWCASTLE HASTALIĞINA KARŞI AŞILAMA DENEMELERİ
}

\author{
Mehmet AKAN \\ Oktay KESKIN \\ Ziya ILHAN $N^{3}$ \\ Asiye DAKMAN ${ }^{3}$ \\ Lale $K \ddot{O} K C ̧ \ddot{U}^{3}$
}

Vaccination studies against Newcastle disease

Summary: The purpose of this study is to determine the humoral immune response of chickens to NCD after vacination with lentogenic strains in different routes and periods by HI test.

The study was performed in 7 groups one of which was the control group. Each group included 50 one-day old chicks. Vaccines (HBI, La Sota, Ma5+Clone 30) were applied to the groups by different routes (spray and drinking water) and at different periods. The group $I$ and 4 were vaccinated on the $7^{\text {th }}$ and $28^{\text {th }}$ days, group 5 and 6 were vaccinated on the first and $28^{\text {th }}$ day. The maternal antibody titer of the one-day old chicks was $7.2(\log 2)$. The HI antibody titers of the groups 1 and 2 were 7.5 on the $3^{\text {rd }}$ week and 6.8 on the $4^{\text {ih }}$ week. On the $6^{\text {th }}$ week. the titer of the group I was 7.7 and the group 2 was 7.8 at the sarne time. On the $3^{\text {rd }}$ week the serum samples of the groups 3 and 4 gave 6.8 HI titer. After the booster the titers of the groups 3 and 4 were 6.9 and 7.1, respectively. The difference between the groups (Group 1-4) was statistically insignificant $(p>0.05)$. Antibody titer of the group 5 and group 6 which were vaccinated by spraying method on the first day was below 7 until the vacination on the $4^{\text {th }}$ week and after the booster antibody titer of the group 5 raised to 7 and group 6 to 7.2. Although the difference between the test groups was found to be insignificant after the $35^{\text {th }}$ day, the difference between the test and control groups was found important after the $2 \int^{\text {th }} d a y$.

Key words: Chicken, Newcastle disease, vaccine, vaccination

Özet: Bu çalısmada, tavuklarm yalancı veba hastalı̆ğna (Newcastle disease. ND) karş lentojenik suslar ile farklı zaman ve uygulamalarla yapilan asslamalar sonrasında oluşan humoral bağışılığın hemaglutinasyon inhibisyon (HI) testi ile belirlenmesi amaçlandi.

Çalışma 50 civcivden oluşan 6'sı deneme ve biri kontrol olmak üzere toplam 7 grupta gerçekleştirildi. Gruplara aşılar $\left(H B_{1}\right.$, LaSota, Ma5+Clone 30) sprey ve içme suyu ile farklı zamanlarda yapıld. Grup 1-4'e cisllar 7-28. günlerde, Grup 5 ve 6'ya I-28 günlerde uyguland. Civcivlerin ilk gün maternal antikorları 7.2 (log2) olarak saptand. Grup I ve 2'de HI antikor titrelerinin 3. haftada 7.5, 4. haftada 6.8, 6. haftada Grup I'de 7.7 ve Grup 2'de 7.8 olduğu belirlendi. Grup

I : Doç. Dr.. 2 :Dr., 3 : Araş. Gör., Ankara Üniversitesi, Veteriner Fakültesi. Mikrobiyoloji Anabilim Dalı, (16 Il0 Dıșkapı. Ankaria 
3 ve 4 'te antikor titrelerinin 3. haftada 6.8 ve ikinci asslamays takip eden dönemde Grup 3'de 6.9 ve Grup 4'te 7.1 olduğu gözlendi. Bu gruplar (Grup 1-4) arasindaki fark istatistiksel açıdan önemsiz. bulundu $((p>0.05)$. Ilk gün sprey aşlama yapulan 5. ve 6. gruplarda antikor titresinin 4. haftadaki asllamaya kadar 7'nin altunda kaldı̆̆ ve ikinci aşllamay takiben 6. hafiada Grup 5'te 7, Grup 6'da ise 7.2 sldus̆u saptandi. Deneme gruplarinin antikor titreleri arasindaki farklar 35. gün ve sonrasinda önemsiz. bulunurken ( $p>0.05)$, deneme ve kontrol grubu arasindaki farklar 2l. gün ve sonrasinda önemli bulundu $(p<0.001)$.

Anahtar kelimeler: Tavuk, Yalancı veba, aşı, aşılama

\section{Giriş}

Newcastle hastalığı (Yalancı veba), Paramyxoviridac familyasına bağlı Avian $\mathrm{Pa}-$ ramyxovirus Tip- 1 tarafindan oluşturulan çok bulaşıcı ve ölduiruicü scyreden viral bir haslalıkur. Hayvanlarda solunum, sindirim ve sinir sistemlerinde bozukluklarla karakterizedir. Hastalığa, tavuklar başta olmak üzere 20('ü aşkın kanatlı tuiruinün duyarlı olduğu saptanmıştır $(1,8,25)$.

Newcastle salgınları dünyada halen belirli boilgclerdc ortaya çıkmaktadır ve önemli ekonomik kayıplara neden olmaktadır. Türkiye'de ilk Newcastle salgınının 1946 yılında tanumlanmasından sonra, hastalık günümüzde de halen belirli bölgelcrde ortaya çıkmaktadır (7.28).

Newcastle hastalığından korunmada canlı ve inaklif aşılar, 1930'lu yıllardan bu yana kullanılmaktadır. Hastalığın aşılı sürülerde hafif solunum sistemi ve sinirsel belirtilerlc ortaya çıktığ bildirilmektedir $(1,25)$. Kanatlı hayvanlarda aşılamalar ile bu hastalığa karşı iyi bir koruma sağlamak için maternal antikor seviyesi, hayvanlarda immun sistemin gelişimi ve immun sistemi basklayan herhangi bir inicksiyonun bulunmaması önemlidir $(1,6,8,20)$. Temel olarak Newcastle hastalı̆̆ıa karşı üç tip ał̧ı kullanılmaktadır. Bunlar canlı lentojenik, canlı merojenik ve inaktif aşlardır $(1,7,25)$. Ayrica son yıllarda rekombinant aşılar da geliş̧irilmiştir $(21,27,31,34)$. Canlı lentojenik aşılar diişiik patojeniyc sahip; fakat, ycterli ba乌̆ışıklık sağlayabilen aşılardır. Bunlar arasında geniş kullanıma sahip Hitchner $B_{1}$, LaSota, Clone 30 ve daha sınırlı kullanılan $F$ ve $V 4$ suşları bulunmakıadır $(1,9,22,25)$. Bu aşılar, hay- vanlara bireysel olarak gözc damlatma ve gaga daldırma şeklinde uygulanmasının yanında pratik olması nedeniyle daha çok içme suyu, spicy ve aerosol yolla kullanılmaktadır $(1,25,30)$. Ayrıca aşılar, kanatlı yemleri ile de verilmcktedir $(23,24)$. Mezojenik suşların aşı olarak kullanımı bir çok ülkede sınırlandırılmış olsa da bazı Asya ülkelerinde halen kullanılmaktadır. Bu suşlar yüksck dïzcyde sekonder bağışıklık săğlamasına karşın hayvanlarda klinik semptomlara da neden olmaktadır. Bu suş̧lar arasinda Roakin, Mukteswar, Komarow ve $\mathrm{H}$ sayılabilir. Canlı mezojenik àşlar genellikle içme suyuna cnder olarak da taban yastığına intra dermal olarak uygulanmaktadır $(14,25)$. Inaktif aşılar, genellikle formalin veya betapropiolakton gibi farklı inaktivatörlerle muamcle edilerek hazırlanmakta ve hayvanlarda yüksek titrede antikor oluşturmak için kullanılmaktadır. Inaktif aşılar kas içi ve deri alı olarak uygulanmakta $(5,15,26,29,32)$, deneysel olarak in ovo yolla da kullanılmaktadır (33).

Günümüzde broiler sürülcri gencllikle canlı lentojenik suşlarla aşlanmaktadır. İnfeksiyonun bölgedcki dağılımı, risk faktörleri, işletmenin biçimi gibi nedenlere bağlı olarak aşılama günleri ve sayıları değişmektedir $(1,3,4,16)$. Hayvanlarda maternal antikorların saptanması ile ilk aşlama gününün ve sonrasında uygulanan aşılama ile oluşan bağışıklığın belirlenmesi bu hastalığın verebileceği olası kayıplan önlemede önem taşımaktadır. Bu çalışmada, lentojenik suşlarla farklı zaman, aşı ve yollarla yapılan aşılamalar sonrasında oluşan humoral bağışıklığın hemaglutinasyon inhibisyon (HI) testi ile belirlenmesi amaçlanmıştır. 


\section{Materyal ve Metot}

Civciv: Çăışmada 50 adedi maternal antikor düzeyini belirlemede ve 350 adedi denemelerde olmak üzerc toplam 400 Ross PM3 civciv kullanıldı.

Aşl: Hitchner Bl (Intervet), LaSota (Intervet) ve Ma5+Clone 30 (Newcastle+Infeksiyöz bronşitis, Intervet) aşıları kullanıldı.

Kümesler: Çalışmada kullanılan hayvanlar birinci günde tesadüfi olarak 6'sı denemc l'i kontrol olmak iizere 50'şerli gruplara aynıldı ve ayrı odalara yerleştirildi. Hayvanlar 49.güne kadar beslendi ve haftalık periyotlarda antikor diizeyini belirlemck amaciyla kanları alındı.

Aş̧lama: Civcivler sprey ve içme suyu olmak iizere iki şekilde aşıland. Sprey aşılama için aşı distile su ile hazırlandı ve uygulama $\mathrm{cl}$ sprey aleti ile yapıldı. Içme suyu ile aşı, hayvanların 2 saat susuz birakılmasinı takiben ve 2 saatte bitirebilecekleri kadar hacimde sütozu içeren distile su ile verildi. Ilk aşılamalann tümuinde $\mathrm{HB}_{1}$ aşısı kullanıldı.

Aşılama programı: Gruplara ayrilan civcivlere uygulanan aşılar ve zamanlan aşağıdaki gibidir. Tüm gruplardaki hayvanlara ayrica Gumboro aşısı (D78, Intervet) da içme suyu ile yapıld.

Grup 1. 7.gün HB1 sprey, 28.gün Clone30+ Ma5 sprey

Grup 2. 7.gün HBl sprey, 28.gün LaSota sprey

Grup 3. 7.gün HB1 içme suyu, 28.gün Clone 30 + Ma5 içme suyu

Grup 4. 7.gün HB I içme suyu, 28. gün LaSota içme suyu

Grup 5. 1.gün HB1 sprey, 28.gün Ma5+Clone 30 içme suyu

Grup 6. 1.gün HBl sprcy, 28.gün LaSota içme suyu

Kontrol. Hiçbir aşı uygulaması yapılmadı

Hemaglutinasyon inhibisyon (HI) testi: Civcivlerde maternal antikorlan saptamak için ilk gün ve aşılamalar sonrasında oluşan ba- ğışıklığı belirlemek amacıyla her hafta kan alınd. Alınan kanların serumlanı çıkarıldı ve antikor düzeyini belirlemek amacıyla $\mathrm{HI}$ testi yapıldı (2,6). Test, U tabanlı 96 gözlii mikropleytlerde (Greiner) gerçckleştirildi.

Istatistik: Her dönemdeki sonuçların değerlendirmesinde tek yönlü varyans analizi (ANOVA) uygulandı. Önemlilik belirlenen dönemlerde, önemliliği oluşturan grupların belirlenmesi için Duncan test kullanıldı. Analizler SPSS paket programı kullanılarak gerçekleştirildi.

\section{Bulgular}

Yapılan aşlamalar sonrasında gruplarda elde cdilen HI titreleri haftalara göre Tablo 1 de sunulmuştur. Antikor titrelerinin karşılaştırmalı sonuçları Şekil 1.de gösterilmiştir. Gruplarda meydana gelen ölümler dencme gruplarında ve kontrol grubunda sirasiyla $3,2,4,1,4,2$, ve 3 adet oldu.

Civcivlerin ilk gün maternal antikorlanı 7.2 olarak saptandı. Bu değer aşılama yapılmayan kontrol grubunda 1 haftada 5.4, 3.haftada $4.4 \mathrm{ve}$ 4. haftadan sonra 4 degerinin altında saptand.

Grup 1 ve 2'de 7.günde yapılan aşılamalar sonrasında aşılamayı takip cden 3.haftada antikor titresinin 7.5 olduğu ve bir hafta sonraki düzeyinin ise 6.8 olduğu belirlendi. Ikinci aşslamadan sonra antikor titresinin 6.haftada Grup 1'de 7.7 ve Grup 2'de 7.8 olduğu bclirlendi. Antikorların HI titreleri bakımından iki grup arasında fark saptanamadı ( $\mathrm{p}>0.05)$.

Grup 3 ve 4'te ise 7.günde içme suyu ile yapılan aşılamalar sonrasında titrenin 3.haftada 6.8 olduğu ve ikinci aşılamayı takip eden dönemde Grup 3'de 6.9 ve Grup 4'te 7.1 olduğu gözlendi Gruplar arasındaki fark istatistikscl açıdan önemsiz bulundu ( $p>0.05)$.

Ilk gün sprey aşılama yapılan 5. ve 6. gruplarda antikor titresinin 4.haftaki aşlamaya kadar 7 'nin altında kaldığı saptandı. Ikinci aşılamadan sonra antikor titreleri 6.haftada Grup 5'te 7, Grup 6'da ise 7.2 olarak saptand. Ikj grup arasında antikor titrelcri arasındaki farkın önemli olmadığ bclirlendi ( $p>0.05$ ). 
Tablo. 1. Kan serumlarının ortalama $\mathrm{HI}$ titreleri $\left(\log _{2}\right)$ ve istatistik bulguları

Table 1. Mean HI titers of blood sera $\left(\log _{2}\right)$ and statistic results.

\begin{tabular}{|c|c|c|c|c|c|c|c|c|}
\hline & 1 gü & 7. gun & 14. gün & 21. gün & 28. gün & 35. güin & 42. guin & 49. gun \\
\hline Grup No & $\bar{x} \pm S x$ & $X \pm S x$ & $X \pm S x$ & $\bar{X} \pm S x$ & $\bar{X} \pm S x$ & $\bar{X} \pm S x$ & $\bar{X} \pm S x$ & $\bar{x} \pm S x$ \\
\hline 1 & $7.20^{\mathrm{A}} \pm 0.20$ & $5.40^{\mathrm{i}} \pm 0.37$ & $5 .(0)^{\mathrm{a}} \pm 0.21$ & $7.56^{\mathrm{c}} \pm 0.62$ & $6.80^{c} \pm 0.46$ & $7 .(0)^{\mathrm{h}} \pm 0.52$ & $7.70^{\mathrm{h}} \pm 0.60$ & $7 .(k)^{k} \pm 0.52$ \\
\hline 2 & $7.2\left(0^{a} \pm 0.20\right.$ & $5.40^{\mathrm{a}} \pm 0.37$ & $5.00^{\mathrm{a}} \pm 0.21$ & $7.56^{\mathrm{c}} \pm 0.62$ & $6.80^{\circ} \pm 0.41$ & $7.10^{\mathrm{h}} \pm 0.4 \mathrm{x}$ & $7.800^{\mathrm{h}} \pm 0.53$ & $7.20)^{k} \pm 0.42$ \\
\hline 3 & $720^{4} \pm 0.20$ & $5.40^{\mathrm{a}} \pm 0.45$ & $5.00^{\mathrm{a}} \pm 0.26$ & $6.80^{\mathrm{hc}} \pm 0.39$ & $6.40^{\circ} \pm 0.37$ & $6.90^{\mathrm{b}} \pm 0.38$ & $7.40^{\mathrm{h}} \pm 0.48$ & $6.80)^{\mathrm{t}} \pm 0.44$ \\
\hline 4 & $7.2\left(0^{4} \pm 0.20\right.$ & 5.4()$^{\mathrm{a}} \pm 0.45$ & $5 .(0)^{\mathrm{a}} \pm 0.26$ & $6.80^{\mathrm{bc}} \pm 0.39$ & $6.40^{b x} \pm 0.26$ & $7.10^{b} \pm 0.53$ & $7.50^{\mathrm{b}} \pm 0.62$ & $7 .(14)^{k+} \pm 0.5 x$ \\
\hline 5 & $7.20^{4} \pm 0.20$ & $5.00^{a} \pm 0.33$ & $6.20^{\mathrm{h}} \pm 0.29$ & $6.00^{\mathrm{b}} \pm 0.26$ & $5.60^{h} \pm 0.22$ & $6.20^{b} \pm 0.30$ & $7.00^{\mathrm{h}} \pm 0.50$ & $6.70^{\mathrm{r}} \pm 0.42$ \\
\hline 6 & $7.20^{4} \pm 0.20$ & $5 .(0)^{\mathrm{a}} \pm 0.33$ & $6.20^{b} \pm 0.29$ & $6 .(x)^{\mathrm{h}} \pm 0.26$ & $5.60^{\mathrm{h}} \pm 0.30$ & $6.20^{\mathrm{h}} \pm 0.30$ & $7.20^{\mathrm{h}} \pm 0.44$ & $6.800^{k} \pm 0.36$ \\
\hline 7 & $7.20^{4} \pm 0.20$ & $5.40^{3} \pm 0.31$ & 4.4()$^{\mathrm{a}} \pm 0.16$ & $3.000^{\mathrm{a}} \pm 0.00$ & $3.00^{\Delta} \pm 0 .(X)$ & $3.000^{\mathrm{a}} \pm 0.00$ & $3.000^{4} \pm 0.00$ & $\left.3.000^{3} \pm 0.00\right)$ \\
\hline$p$ & - & - & $* * *$ & $* * *$ & $* * *$ & $* * *$ & $* * *$ & $* *$ \\
\hline
\end{tabular}

p<0,()()!:

Onemli değil

i. B. c A A vm sulunda farklı harf taşyan grup ortalamaları arass fark inemli
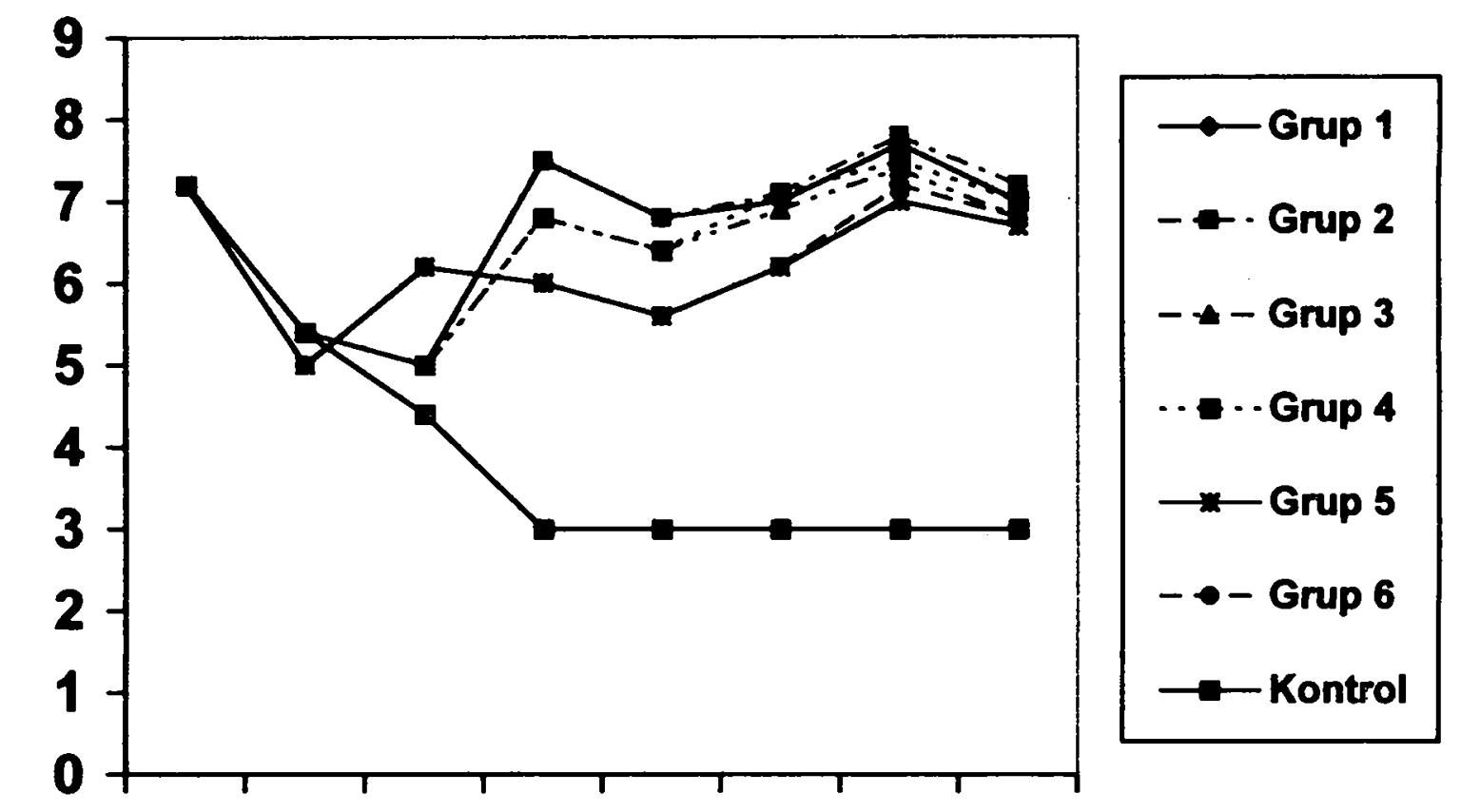

Şekil 1. HI titrelerinin karşılaşurmalı sonuçları

Figure 1. Comparative results of HI titers 
İstatistik bulguları: Parametrik olmayan Kruskal-Wallis ile parametrik tck yönlü varians analizleri sonuçları birbiriyle uyumlu bulunmasından dolayı, parametrik test sonuçları değerlendirilmeye alındı. Gruplar arası farklığın belirlenmesinde önemlilik oluşturan dönemlerde Duncan testi ile farklığı oluşturan grup(lar) belirlendi. Istatistik bulgulan Tablo 1.de sunulmuştur. Gruplar arasında HI antikor titrelcri 7.gün itibariyla istatistiksel anlamda önemsiz $(p>0.05)$ bulundu. Ikinci hafta ve sonrasındaki haftalarda, Grup 1-4 arasında fark önemsiz iken Grup 1-4 ile Grup 5 ve 6 arasındaki fark anlami bulundu $(\mathrm{p}<0.001)$. Üçüncii hafta ise Grup 1-2 ile Grup 5-6 arasındaki fark öncmli bulunurken ( $p<0.001$ ), diğer gruplar arasındaki fark önemsiz bulundu ( $p>0.05$ ). Kontrol grupları ile diğer gruplar arasındaki lark, 3.haftadan sonraki testlerde anlaml bulundu ( $p<0.001)$. Beşinci hafta ve sonraki analizlerde deneme grupları arasındaki fark önemsiz bulunurken $(p>0.05)$ sadece deneme grupları ile kontrol grubu arasıdaki fark önemli bulundu $(p<0.001)$.

\section{Tartışma ve Sonuç}

Newcastle hastahı̆ının tavuk yetiştiriciliği için oldukça önemli bir hastalık olduğu ve hastalığın verebileceği olası kayıpların önlenmesinin ancak iyi bir aşılama programı ile aşılabileceği bir gerçektir. Bu çalışmada, tavukların yalancı veba hastalığına karşı farklı yöntem ve kombinasyonlar ile aşılanan broilcrlcrde oluşan antikor yanitı HI testi ilc belirlendi.

ND aşılama programlarının oluşturulmassında birçok faktör bulunmaktadır. $\mathrm{Bu}$ faktörler arasında, hastalığın çevredeki dağllımı, maternal antikor düzeyi, hayvanların yeliştirilmc yönü, hayvanların yaşları, iklimsel koşullar ve hayvanlara uygulanan genel aşılama programı sayılabilir. Yapılacak aşılamalar sonrasında ND için antikor düzeyinin HI testinde suirii ortalamasının $\log _{2} 7$ değerinin üzcrinde olması gerektiği bildirilmektedir $(3,4,6)$. Bu değcre ulaşmak ve sonrasında bu düzcyde bir antikor scviyesini sürdürmek hastalığa karşı guivenli bir eşik olarak kabul edilmektedir.
Broilerlerin aşılanma zamanlarının belirlenmesi için maternal antikor düzeyi oldukça önem taşımaktadır. Bu nedenle entegrasyonlarda veya bircysel kümeslerde mutlaka anaçların ND aşılama programlarının bilinmesi veya antikor dizeylerinin periyodik olarak belirlenmesi önemlidir. Bu çalışmada maternal antikor düzeyinin ilk gün $\log _{2} 7.2$ olduğu saptandı. Maternal antikor diizeyinin ilk gün yüksek olmasına karşın, ilk hafta sonunda 5.4'e ve 3.haftada ise 4 değerinin altına düştiiğ ii gözlendi. Bu sonuçlar maternal antikorların çok hızlı bir yarılanma ömrü olduğunu göstermcktedir.

Maternal antikor düzeyinin aşılama sonrasında oluşan bağışıklığı etkilediği bilinmektedir. Konuyla ilgili çalışmalarda, yuiksek maternal antikorların varlığında yapılan aşılamalar sonrasında antikor yanıtının olumsuz etkilendiği bildirilmiştir $(6,11,17,20,29)$. Bu çalışmada farklı maternal antikor seviyelerinde yapılan aşılamalarda değişik sonuçlar alındı. Maternal antikor seviyesi 7.2 olduğu ilk gün yapılan sprey aşılamada antikor düzcyinin ancak 42.günde ve ikinci aşılamadan sonra koruyucu duizey olarak belirlenen $\log _{2} 7$ değerinin izzerine çıktığı gözlendi. Maternal antikor diizeyinin birinci haftada $\left(\log _{2} 5.4\right)$ yapılan ilk aşılamayı takiben iki hafta sonra antikor düzcyinin sprey aşılamalarda $\log _{2} 7$ değcrinin üzerinde olduğu, içme suyu aşılamalarında isc $\log _{2} 7$ değcrine oldukça yakın bir titrcye ulaştığı gözlendi. Ayrıca bu gruplarda ikinci aşılamalardan sonra antikor titresinin hayvanlann kesim tarihine kadar $\log _{2}$ 7 degerinin üzerinde olduğu saptandı. Elde edilen bu sonuçlar, yüksek maternal antikorlar düzeyinde yapılan aşılamalar sonrasında antikor titresinin düşük kaldığı, buna karşın maternal antikor düzcyi $\log _{2} 7$ 'nin altındaki titrelerde yapılan aşılamalarda ise yüksck antikor yanıtı oluştugunu göstermekte ve konu ile ilgili araştırma sonuçlannı desteklemektedir.

Broiler sürülerinde genel bir yaklaşım olarak iki canlı aşının yapılması önerilmektedir $(2,25,28)$. Bu çalışmada, haftalık yapılan kontrollerde Grup 1-4'te ilk aşlamalar sonrasinda oluşan antikor titrelerinin 28. günde düşmeye başladığı belirlendi. Elde edilen bu sonuç ND'ye karşı broilcrler için tek bir aşının ycterli 
bağıı̧ıklık sağlayamadığını gösterdi. Ikinci ND aşısının tüm gruplarda 28 . guinde yapılmasını takiben antikor titresinin yükseldiği ve kesime kadar koruyucu titre olarak kabul edilen $\log _{2} 7$ değerine yakın seviyelcrde olduğu gözlendi. Allan ve Gough (2), tavuklanı ND'ye karşı korumada bir aşının yeterli olmayacağını ve mutlaka birden fazla canlı aşının kullanılması gerektiğini bildirmişlerdir. Gümüşsoy (19) da, iki aşlama sonrasında hayvanlarda yüksek antikor diizeyini saptamıştır. Bu araştırmada elde ediIen sonuçlar da, broiler sürülerde iki ND canlı aşısının ycterli bir bağışıklık oluşturabildiğini göstermektcdir.

ND aşılamaları birçok yöntemle yapılabilmektedir. Yöntemler arasında, aşılamalar sonrasında oluşan antikor titreleri bakımından larklılıklar ortaya çıkmaktadır. Rehmani (30), LaSola, F ve Mukteswar suşları ile içme suyu ve intraokiiler aşılamalar sonrasında oluşan antikor titrelerini HI ile değcrlendirdiği çalışmasında, intraokuler aşılamalarda içme suyu aşılamalarına göre daha iyi sonuçlar aldığını ve sonuçlar arasındaki farkın istatistiksel olarak onemli olduğunu bildirmişdir. Partadiredja ve ark. (29), broiler damızlıklarında sprey aşılamanın, intratrahcal ve içme suyu ile aşılamalara göre daha iyi titrede antikor oluşLurduğunu ve saha virusu ile infeksiyona göre tavukların daha dirençli olduğunu göstermişlerdir. Benzer sonuçlar Arda (6), Eidson ve Kleven (12) ve Gough ve Alexander (18) tarafindan da desteklenmektedir. Bu çalışmada sprey aşılamalar sonrasında elde edilen $\mathrm{HI}$ antikor titreleri Grup 1 ve 2 de, diğcr gruplara göre yüksek bulundu. Fakat elde cdilen sonuçlar arasında fark istatistiksel olarak önemsiz olduğu saptandı $(p>0.05)$. Bu araşturmada eprüvasyon çalışması yapılmadığından dolayı farklı yöntemlerle yapılan aşılamaların saha virusuna karşı koruyuculuğu hakkında bir sonuca varılamadı. Çalışmada HI titreleri dikkate alınarak yapılan değerlendirme sonucunda sprey aşllamalarda elde edilen yuiksek antikor seviyesi diğer araştırıcıların sonuçları ile uyumlu bulundu.

Broiler yetiştiriciliğinde sürenin çok az olması ve ozellikle riskli bölgelerde yoğun aşılama programlarının uygulama zorunluluğu ne- deniyle bazı aşıların kombine kullanılmasını ge rekli kılmaktadır. Bu uygulamanın en sık kullanılanı ND aşılarının IB aşıları ile kombine edilmesidir (10). Bu uygulamayı düşuinerek, çalışmada üç gruba ikinci aşılar IB aşısı ile kombine olarak yapılmıs ve elde edilen antikor diizeyleri karşılaştırılmışır. Bu çalışmada, kombine aşı kullanılan Grup 1, 3 ve 5 'in an tikor titreleri sırasiyla Grup 2, 4 ve 6’ya göre daha düşük bulunmasına karşın fark istatistiksel olarak önemsiz bulundu ( $p>0.05$ ). Elde edilen bu bulgulara göre bölgedeki hastalıkları iyi bilinmesi ve bu bilgiler doğrultusunda aşıların kombine ya da ayrı olarak kullanılması yoluna gidilmelidir.

ND'ye karşı aşılama sayıları hastalığın yaygınlığına ve kümesin şartlarına göre değişebilmektedir. Bazı bölgelerde bir aşı uy gulanırken, bazı işletmelerde iki aşı kullanılmaktadır. Fakat hastalığın sahada yaygın olduğu durumlarda birçok araşırıcı işletmelerde, kuluçkada veya kümeste ilk güin aş1lama yapılmasını ve buna bağlı olarak da broileriere üç aşının ya da inaktif aş̧ların kullanılmasının gerckli olduğunı bildirmcktedirler $(13,25,28)$. Bu çalışmada ilk aş1lamanın birinci gün yapılmasını takiben antikor titresinin ancak ikinci aşlamadan sonra 6.haftada koruyucu titre olarak belirlenen $\log 2$ 7 değerine ulaşı̆̆g belirlendi. Bu şekilde aş1lanan civcivlcrin antikor seviyeleri özelikle 2-4 haftalarda oldukça diişuik kalmaktadır. Elde edilen bu sonuçlar ilk güin aşı yapılan broiler civcivlere yaşamları boyunca uiç aşının yapılması gerektiği görüşünui destekler niteliktedir.

Sonuç olarak, sahada çok farklı şekillerde uygulanan aşlanın ve aşlama programlarının oluşturulmasında, maternal antikorun en temel bileşen olduğu ortaya konmuştur. Ayrica uygulama metotlan arasında istatistiksel olarak önemli bir farkın olmaması da önemli bir sonuçtur. $\mathrm{Bu}$ çalışmada elde edilen bir başka sonuç da, kombine olarak kullanılan ND+IB aşılamalarında HI titreleri arasında istatistiksel olarak bir fark olmamasıdır. Bu nedenle sahadaki risk durumunda bu iki hastalığa karşı kombinc aşı uygulamaları yarar sağlayacaktır. 


\section{Kaynaklar}

I. Alexander, D.J. (1997) Newcastle disease and other avian paramyxoviridat infections. In: Diseases of Poultry., p:541-569. Ed: Calnck, B.W. Tenth Ed. Iowa Stitle Univ.. Iowa.

2. Allan, W.H., Gough, R.E. (1924) A standard haenagglutination inhibition test for newcastle disease (1). A comparison of macro and micro methods. Vet Rec. 95, 12()-124.

3. Akçadağ, B., Arda, M., Aydın, N., Akay, Ö., İzgür, M. (1984) Newcastle hastalığına karşı asslama denemeleri. A U Vet Fak Derg, 31, 293-303.

4. Akçadağ, B., Akay, Ö.,Aydın, N., Arda, M., İzgür, M. (1984): Newcastle hastaltğna kaiss asilama denemeleri. A U Vet Falk Derg, 31, 333-345.

5. Alfonso, P., Noda, J., Varela, N., Pedroso, M. (1996) Befa-1.3 slacano y manano com adyavantes de vacunas inaktivadas de Newcastle. Rev Salud Anim. 18. 173-175

6. Arda, M.(1976) Hollanda'da Newcastle hastallğ üzerinde çalısmalar ve HI testinin yeni yönteme göre degertlendirilmesi. Vet Hek Derg, 46, 19-28.

7. Beard, C.W., Hanson, R.P. (1984) Newcastle Disease. Pg-452-470. Fd. Hofsad, M.S., Barnes, H.J., Calnek. B.W.. Reid, W.M., Yoder, H.W.Jr., Diseases of Poultry. 8th ed., Iowa State Univ.Press, Ames, lowit

8. Bcll, I.G., Nicholls, P.J., Norman, C., Cross, G.M. (1991) Natural infection of broiler breeder chickens with endenic apathogenic Newcastle disease virus and their suhsequent response to vacination with V4 Newcaslle disease virus vaccine. Aust Vet J, 68, 93-96.

9. Cajavec, S., Bidin, Z., Sladic, D)., Pocric, B. (1996) Tween $8(0$-solubilized Newcastle disease virus prepared as a water in oil in water vaccine. Avian Dis. 40. 193-2()!.

10. Cavanagh D., Nagi, S.A. (1997) Infectious bronchitis. Pg: 511-526. Ed: Calnek, B.W. Diseases of Poultry, Tenth Ed. lowa State Univ, Iowa.

11. Kidson C.S., Kleven, S.H., Villegas, P. (1976) Efficacy of intratrecheal administration of Newcastle disease vaccine in day old chicks. Poultry Sci, 55, 12521267.

12. Eidson C.S., Kleven, S.H. (1976) A comparison of varuns forutes of Newcastle disease vaccination at one day of age. Poultry Sci, 55. 1778-1787.

13. Erganiş, O., Okur, A., Çiçek, S. (1997): Newcastle hastallŏ̌na karș inaktif aşlarln kullanilmasında laboratuar ve saha sonuçlarıman değerlendirilmesi. VeLerinatium, 8.57-59.

14. Ergün, A., Aydın, N., İzgür, M. (1985) Newcastle haslaliğina kar,st Rrakin ast uygulamast sonucu ortaya sikan aş stresi üzerinde arasstermalar. Doga Bil Derg. 1. 157-165.

15. Folitse, R., Halvrson, D.A., Sivanandan, V. (1998) Efficacy of combined killed in oil emulsion and live Newcastle disease vaccines in chickens. Avian Dis, 42, 173-178.
16. Gambrone, J.J. ( 1984) Laboraton evaluation of newcastle disease vaccination programs for brotler chickens. Asvian Dis, 29, 479-487.

17. Giambron, J.J., Closser, J. (1990) Effect of breeeder vaccination on imunization of progeny arainst Newcastle diseuse. Avian Dis, 34, 114-119.

18. Gough, R.E., Alexendar, D.J. (1973) The spreed of resistance to chalenge induced in chickens vaccinated by different routes with a BI strain of live NDV. VCt Rec, 92, 563-564.

19. Gümüşsoy, K.S. (1997) Kanatllarda Newcastle hastalığına karsı göz ve burum yoluyla asslamalartn karşlaşırılması. Doktora Tezi. A Ü Sağglikbilimlcri Enstitijsii, Ankara.

20. Halvorson, D.A., Shaw, D., Sivanandan, V., Barbour, E.K., Maheshkumar, S., Newman. J.A., Newman, L. (1991) Serological response in broiler chacks to different commercial Newcastle disase and infectious bronchitis vaccines. Avian Dis. 35, 978-981.

21. Heckert, R.A., Riva, J., Cook, S., Mcmillen, J., Schwartz, R.D. (1996) Onset of protective immunity: in chicks after vaccination with arecombinant herpes virus of lurkeys vaccine expressing Newcastle disease virus fusion and hemaglatinin neuraminidase antigens. Avian Dis, 40, 77()-777

22. Hofacre, C.I.., Villegas, P., Page, R.K. (1985) Newcastle disease vaccination of broilers with hish and low titered commercial vaccines. Avian Dis. 30. 623627.

23. Ideris, A., Ibrahim, A.L., Spradbrow, B.P. (199()) Vaccination of chickens against Newcastle disease with a food pellet vaccine. Avian Pathol, 19. 37 I-384.

24. Jayawardane, G., De Alwis, M., Bandara, D. (199()) Oral vaccination of chickens against nencastle disease with V4 vaccine delivered on processed rice grains. Aust Vet, J, 67, 364-366.

25. Jordan, F.T. (1996) Poultry Disease-4 $4^{\text {th }}$ ed.Pg: 460)483. WB Saunders Company Lid, London.

26. Mahboob, T., Arshad, M., Afzal, H., Siddıque, M., Muharmmad, G. (1997) Preparation and evaluation of Newcastle disease oil emulsion vacines at hidrophilelipophile balance 7.0 using LaSota strain - a preliminary trial. Pakistan Vet J. 17. 127-130.

27. Nagy, E., Krell, P.J., Dulac, G.C., Derbyshire, J.B. (1991): Vaccination against Newcastle disease with a recombinant baculovirus hemagglatinin- neuroaminidase subunit vaccine. Avian Dis. 35. 585 590 .

28. Özdemir, 1. (1992) Current new-castle disectse stiuation in Turkey. Workshop On Avian Paramywovirus. Proceedings. Rauuschhollzhausen, 109-116. July 27 29, Germany.

29. Partadiredja, M., Eidson, C.S., Kleven, S.H. (1978) Immunization of broiler breeder ckickenss asain.st Nen'castle disease with an oil-emulsion vaccine. Avian Dis, 23, 597-607.

30. Rehmani, S.F. (1996): Newcastle disease vacimation: A comparision of vaccines and routs of administration in Pakistan. Preventive Vet Med, 25, 241-248. 
31. Sakaguchi, M., Nakamura, H., Sonoda, H., Okamura, H., Yokngawa, K., Matsuo, K., Hira, K. (1998) Protection of chickens with or without maternal antibodies against both Marek's and Newcastle diseases by one time vaccination with recombinant vaccine of Marek's disease virus type I. Vaccine, 16, 472479.

32. Stone, H.D. (1997) Newcastle disease oil emulsion vacines prepared with animal, vegetable and synthetic olls. Avian Dis, 41, $591-597$.

33. Stone, H., Mitchell, B., Brugh, M. (1997) In ovo vaccination of chicken embryos with experimental Newcastle disease and avian influenza oil-emulsion vaccines. Avian Dis, 41, 856-863.
34. Taylor, J., Christensen, L., Getting, R., Goebel, J., Bouquet, J.F., Mickle, T.R., Poletti, E. (1996) Efficacy of arecombinant fowl-pox-hased Nencastle disease virus vaccine candidate against velossenic and respiratory challenge. Avian Dis 40, 173-180.

\section{Yazışma Adresi}

Doç.Dr. Mehmet AKAN

Ankara Universitesi Veteriner Fakültesi

Mikrobiyoloji Anabilim Dalt

O6110 Diskapı ANKARA 